\title{
Letter to the editor: Trends in human leptospirosis in Denmark, 1980 to 2012
}

M Goris (m.goris@kit.nl)1, R Hartskeerl'1

1. Royal Tropical Institute (KIT), KIT Biomedical Research, WHO/FAO/OIE . National Collaborating Centre for Reference and Research on Leptospirosis, Amsterdam, the Netherlands

Citation style for this article:

Goris M, Hartskeerl R. Letter to the editor: Trends in human leptospirosis in Denmark, 1980 to 2012. Euro Surveill. 2015;20(9):pii=21053. Available online: http:// www.eurosurveillance.org/ViewArticle.aspx?Articleld=21053

Article submitted on 24 February 2015 / published on 05 March 2015

\section{To the editor:}

We have read with interest the recent article by Van Alphen et al. [1]. It is a very informative paper about the leptospirosis situation in Denmark, which contributes to increased insight in leptospirosis in Europe.

As the authors state correctly in the Methods section, serovar Patoc is non-pathogenic and therefore does not cause leptospirosis in humans but can act as a marker for a leptospiral infection. Remarkably, however, the abstract mentions Patoc to be the predominant serogroup diagnosed over time. This may confuse readers who are unfamiliar with leptospirosis. Besides, serovar Patoc belongs to serogroup Semaranga; there is no serogroup named Patoc. To assess the temporal and spatial distribution of serogroups in Denmark, titres against Patoc should have been ignored and data be based on only agglutination titres with pathogenic serovars. In case none of these have a positive titre (note that $\leq 1: 100$ indicated as cut-off titre should be $\geq 1: 100$ ) the label 'probable infecting serogroup could not be determined' would be appropriate.

The authors mention that the severity of acute infection is obvious, but the long-term effects of Leptospirosis are unknown and chronic infections with Leptospira have been previously reported [2]. While this in itself is a contradiction, we would like to stress that persistent complaints after acute leptospirosis receive increasing attention [3].

Interestingly, the authors mention a potential future increase in the incidence because of, among other things, climate change. Did they observe such an increase in the incidence due to autochthonous infections in the previous year(s) as several countries in Europe have done? If not, it would be of interest to know whether this could this be attributed to the suggested prevention measures.
Conflict of interest

None declared.

Authors' contributions

MG and RH wrote the letter together.

References

1. van Alphen L, Lemcke Kunoe A, Ceper T, Kähler J, Kjelsø C, Ethelberg S, et al. Trends in human leptospirosis in denmark, 1980 to 2012. Euro Surveill. 2015;20(4):21019. PMID:25655055

2. Petersen AM, Boye K, Blom J, Schlichting P, Krogfelt KA. First isolation of Leptospira fainei serovar Hurstbridge from two human patients with Weil's syndrome. J Med Microbiol. 2001;50(1):96-100. PMID:11192512

3. Goris MG, Kikken V, Straetemans M, Alba S, Goeijenbier $M$, van Gorp EC, et al. Towards the burden of human leptospirosis: duration of acute illness and occurrence of postleptospirosis symptoms of patients in the Netherlands. PLoS ONE. 2013;8(10):e76549. http://dx.doi.org/10.1371/journal. pone.0076549 PMID:24098528 